\section{Royal Society appointed referee in UK dispute}

THE Royal Society of London, in conjunction with the Norwegian Academy of Science and Letters and the Royal Swedish Academy, has embarked on a five-year study of the contentious problem of acid rain in northern Europe. The development breaks new ground for the society, whose formal studies of public issues have hitherto been confined to uncontroversial topics, those on which its advice has been sought by government or which appeared to lie within the professional interests of its members.

The new study is also unprecedented in that it will be supported to the tune of $£ 5$ million over five years by the two British nationalized industries most likely to be adversely affected by a finding that sulphur dioxide emissions from British power stations are responsible for the disappearance of fish from lakes in Scandinavia. Both the Central Electricity Generating Board and the National Coal Board have agreed to provide up to $£ 2.5$ million each for the study. Its director will be Sir John Mason, who retires as director-general of the Meteorological Office at the end of this month.

The origin of the study appears to rest with Sir Walter Marshall, a fellow of the Royal Society since 1971 and now chairman of the Central Electricity Generating Board. At the announcement of the study earlier this week, he explained that he could not on the basis of the evidence now available agree that emissions from the board's chimneys should be freed from sulphur dioxide at a cost of $£ 4,000$ million, adding some $10-15$ per cent to the cost of generating electricity. Mr Ian MacGregor, the new chairman of the National Coal Board, took the same line earlier this week.

Everybody is anxious to emphasize that the study of acid rain and its effects will be carried out independently both of the sponsors and of the governments concerned. The participation of the Norwegian and Swedish academies is, however, a guarantor of that independence. The planning of the study will be supervised by a management group under Sir Maurice Sugden and will consist of four nominees of the Royal Society and four nominated by the Scandinavian academies (not yet chosen). The announcement says that the results of the new research programme will be published "without restrictions".

The British membership of the management group has the additional interest of including Professor T. R. R. Southwood (Oxford), who is the present chairman of the Royal Commission on Environmental Pollution, supported financially by the government. The other members are $\mathrm{Dr}$ T. F. West, Professor E J. Denton and Dr J. F. Palling (from the Freshwater Biological Association).

The plan is that the study should not be concerned with the airborne transport of sulphur dioxide from one place to another, on the grounds that enough work on that subject is already under way, but that it should concentrate instead on the ef fects of acid rain on land and water. The effects of airborne sulphur dioxide on forest species may also be left aside on the grounds that these are being taken up energetically in West Germany and elsewhere.

In their announcement of the new study, the three academies give as an example of the problems to be investigated the recognition within the past decade that the death of fish in Scandinavian lakes may not be the direct result of acidity as such but rather of the mobilization of aluminium from surrounding catchment minerals.

The Central Electricity Generating
IT seems that 1983 is rapidly becoming a religious year for CERN, the European Organization for Nuclear Research near Geneva, where the intermediate vector bosons (Ws and $Z^{0}$ ) were discovered. $A$ few months ago His Holiness the Pope passed by and gave his blessing; last month it was the turn of the Dalai Lama, spiritual leader of the Tibetan Buddhists.

The Dalai Lama and his retinue had apparently asked to be briefed on the objec-

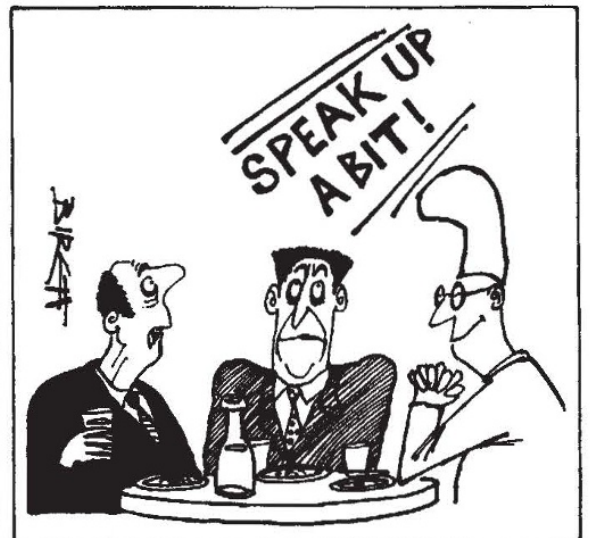

tivity of science, on determinism and quantum mechanics, and on the nature of the vacuum. They were fed this stimulating but somewhat indigestible fare over lunch by the CERN ex-director Leon Van Hove (objectivity), John Bell (determinism) and Maurice Jacob (vacuum).

According to Jacob, the Dalai Lama "had a lot of sharp questions". He was in-
Board, on its own behalf and that of the National Coal Board, refers without dissent to the study by the Organization for Economic Cooperation and Development (OECD) in 1976 which suggested that Britain might be responsible for half the acid deposition in Norway and Sweden.

While guessing that its own chimneys may be responsible for half the sulphur dioxide put into the atmosphere in Britain, the generating board also insists that there is at present no way of calculating how much benefit would result in Scandinavia from a specified reduction of emission from the United Kingdom. The boards also raise the interesting suggestion that the sulphur dioxide concentration of the atmosphere may predate the rapid growth of electricity generating plant in this century.

By their approval of the United Nations convention on long-range transport of air pollutants and its advocacy of research on such problems, the two British boards also implicitly accept responsibility for doing what they can to mitigate such problems as can be laid at their door. By commissioning the Royal Society to carry out the study, they have for practical purposes appointed it the referee in deciding what should be done to abate the nuisance of acid rain. It will be interesting to see how well the society discharges that role five years from now. $\square$

\title{
Dalai Lama visits nuclear physicists
}

terested in the vacuum, Jacob said, because vacuity is an important concept within Buddhism. No object exists to a Buddhist unless it is recognized and distinguished the element of consciousness must enter. But, Jacob explained, there is a big difference between vacuity - complete nothingness - and the physical vacuum, which is obtained when all particles and fields are removed to produce a state of lowest energy. Such a vacuum "has all of physics in it", as it could be polarized - particles and antiparticles created from it - by a probe. What this has to do with consciousness is unclear, but the Dalai Lama went so far as to suggest that science could aid the interpretation of scripture.

The Pope, on the other hand, had been less interested in the philosophy of science and more in its social impact - as befits the relative natures of Christianity and Buddhism. He asked CERN researchers to be vigilant about nuclear war, and to use their expertise to help alert the public to the dangers of nuclear conflict.

Both religious leaders stressed a continuity between science and faith. The more hopeful ecumenicists who favour a rapprochement of all the higher religions may take this as a good sign, for if $A$ is continuous with $B$, and $B$ with $C$, then so is $A$ with $C$, provided $B$ is continuous. Since most scientists believe in the logical - or at least existential - continuity of science, this implies that Christianity is continuous with Buddhism.
Robert Walgate 